\title{
CRYPTOCOCCAL LYMPHADENITIS
}

\author{
A. Talerman*, Jean M. Bradley and B. Woodland \\ Departments of Histopathology and Microbiology, Royal Free Hospital, London
}

Plates LX AND LXI

CRYPTOCOCCOSIS is relatively uncommon. It was once considered a rarity, and Symmers (1953) while reporting two cases could find only eight others in the British literature. By 1955 the world literature contained over 300 cases (Littman and Zimmerman, 1956), and more recently the disease has been recognised and reported with much greater frequency.

The involvement of lymph-nodes in cryptococcosis is considered to be rare (Littman and Zimmerman; Kent and Layton, 1962) and is usually observed in cases where the disease is very widely disseminated (Symmers, 1953; Kent and Layton). In the present case cryptococcal infection led to cervical and mediastinal lymph-node enlargement with extensive caseous necrosis. There was a single subpleural granulomatous lesion and only microscopical evidence of meningitis.

\section{CliniCAL HISTORY}

In April, 1968, the patient, a 56-yr-old man, was found to have diabetes mellitus which, until the terminal illness, was adequately controlled by dietary measures.

He was admitted to the Royal Free Hospital on 19 Aug. 1968 with a 2 weeks' history of shortness of breath and ankle oedema, and 1 week's increasing weakness, the latter preceded by vomiting and diarrhoea of 24 hours' duration. He had had no chest pain and no headache, but complained of a non-productive cough following an attack of bronchitis $18 \mathrm{mth}$ previously.

On examination, he was dyspnoeic at rest with dullness to percussion at the right lung base, without added sounds. The jugular venous pressure was raised by $4 \mathrm{~cm}$, the liver was tender and palpable $3 \mathrm{~cm}$ below the costal margin, there was sacral oedema and ankle oedema extending to the knees. No lymphadenopathy was discovered. The blood sugar was $300 \mathrm{mg}$ per $100 \mathrm{ml}$ on admission, but this was controlled thereafter with oral hypoglycaemic drugs. The heart failure was treated by digitalisation and diuretics, in spite of which the oedema increased. His general condition deteriorated until his death on 11 Sept. 1968.

The laboratory findings included the following: haemoglobin- $14.0 \mathrm{~g}$ per $100 \mathrm{ml}$; WBC $-13,000$ per $\mu$, with a normal differential count; ESR $-16 \mathrm{~mm}$ in $1 \mathrm{hr}$; plasma proteins-5.4 g per $100 \mathrm{ml}$ (albumin $2.9 \mathrm{~g}$ per $100 \mathrm{ml}$; globulin $2.5 \mathrm{~g}$ per $100 \mathrm{ml}$ ). Electrophoresis of serum showed no abnormality apart from low albumin.

Chest X-radiograph showed some cardiomegaly with pulmonary oedema and a small right-sided effusion. Patchy shadowing at the right base was thought to be consistent with bronchopneumonia.

Scanty polymorphs were seen in a specimen of pleural fluid, which yielded no growth from subculture of a brain-heart infusion medium. No specimen of sputum was received for culture. There were no other relevant investigations.

Received 14 Mar. 1970; accepted 6 Apr. 1970.

* Present address: Institute of Pathology, Medical Faculty, Wytemaweg 2a, Postbus 1738, Rotterdam, Holland.

J. MED. MICROBIOL.-VOL. 3 (1970) 


\section{NECROPSY}

The body was of an elderly male of normal build and height. There was pitting oedema of the legs as far as the knees. There was a pericardial effusion $(120 \mathrm{ml})$, pleural effusions $(1100 \mathrm{ml}$ right and $350 \mathrm{ml} \mathrm{left})$ and ascites $(1200 \mathrm{ml})$. The heart was enlarged, weighing $695 \mathrm{~g}$ with marked left ventricular $(1.9 \mathrm{~cm})$ and slight right ventricular $(0.5 \mathrm{~cm})$ enlargement. There were recent and old myocardial infarcts involving the left ventricular wall; the recent infarct was covered by antemortem thrombus. The descending branch of the left coronary artery exhibited an occlusion of recent origin and there was an old recanalised occlusion in the same artery. Other coronary arteries showed a severe degree of atherosclerosis.

There was acute and chronic bronchitis, and the lungs showed emphysematous changes. The left pleura was normal, but the pleura covering the right lower lobe exhibited a number of minute, pale, greyish-yellow nodules $0.2-0.5 \mathrm{~cm}$ in diameter. In the upper part of the right lower lobe near the hilum there was a soft greyish-yellow triangular lesion $(1.5 \times 1.2 \times 0.9 \mathrm{~cm})$ situated subpleurally. There were no other lesions of this type. In addition, the lungs were oedematous and congested and there were pulmonary infarcts of recent origin in both lower lobes. There was antemortem thrombus in the pulmonary artery supplying the right lower lobe. There were also antemortem thrombi in the deep veins of both calves.

There was mediastinal lymphadenopathy, most marked near the right hilum, and there was enlargement of the lower cervical lymph-nodes. The cervical enlargement was bilateral, but was more marked on the right side. The lymph-nodes were firm in consistency, greyish-yellow in colour, measured $3-6 \mathrm{~cm}$ across and were surrounded by fibrous capsules. Cut section showed that the lymph-node masses consisted of matted individual lymph-nodes measuring $1 \cdot 0-2 \cdot 5 \mathrm{~cm}$ across (figs. 1 and 2). The lymph-nodes had a nodular pattern, the nodules containing grey-yellow caseous material in their centres. This material became dislodged in places producing small cavities (fig. 2). The caseous material appeared similar to, but more granular and mucoid than, the necrotic material observed in lymph-nodes affected by tuberculosis. All the other lymph-node groups were normal.

The liver and the spleen were enlarged and congested, but exhibited no other abnormalities. The brain and the meninges appeared normal. There were no other relevant findings.

Microscopical findings. Histological examination confirms the gross findings of myocardial infarction, coronary artery thrombosis, pulmonary oedema and infarction, acute and chronic bronchitis, and emphysema.

Sections from the cervical and mediastinal lymph-nodes confirm the presence of caseation. The nodular pattern observed macroscopically is due to central zones of caseation necrosis surrounded by a narrow rim of granulation tissue (fig. 3). This peripheral region contains epithelioid cells, giant cells both of Langhans and foreign-body type, lymphocytes and plasma cells (fig. 4). External to the granulation tissue there is a zone of fibrosis. There is no evidence of calcification in any of the sections. 
The lesion from the right lower lobe shows appearances similar to those in the lymph-nodes. The minute pleural nodules show a central focus of necrosis surrounded by fibrous tissue with practically no cellular reaction.

Lymph-nodes from other sites are normal. No involvement was observed in any other organs including liver, spleen, adrenals, kidneys, prostate, pancreas and thyroid. The brain was re-examined after 3 weeks' fixation in formolsaline. A large number of sections were taken and examination reveals slight chronic inflammatory-cell infiltration and congestion of the meninges. The inflammation is patchy and varies in intensity; a few small granulomata are present. In many places the meninges appear to be within normal limits. There is no evidence of encephalitis.

Mycology. Gram- and Ziehl-Neelsen-stained sections of the caseous lymphnodes show no bacteria. Periodic acid-Schiff (PAS) staining of the lymphnodes reveals numerous round or oval encapsulated cells $5-10 \mu \mathrm{m}$ in diameter. The organism is Gram-positive and is stained by Grocott's methenamine silver nitrate stain. None of the cells has the broad capsule characteristically associated with Cryptococcus neoformans, but capsular material, stained by the PAS technique and better defined when stained by alcian blue and by mucicarmine, is present and is of about the same thickness as the cell wall. Some of the organisms are budding (figs. 5 and 6) and a few exhibit "pseudo-hyphae" (fig. 6). The organisms are present within the caseous zone, especially at its periphery, but are less abundant in the granulation tissue (fig. 5).

Morphologically similar organisms are present in the pulmonary lesion, but no "pseudo-hyphae" are found in the pleural lesions.

Prolonged search of the meninges reveals only a few organisms, without evidence of budding or of " pseudo-hyphae", but otherwise morphologically similar to those in the lymph-nodes and in the pulmonary lesion.

The positive staining reaction with alcian blue and mucicarmine is typical of cryptococci and is not found with Candida spp.

\section{Discussion}

The clinical diagnosis of cryptococcal infection is often very difficult, even in patients with meningitis (Watkins et al., 1969), and this is even more so when the disease is localised to the lung. In the present case, cryptococcosis was not suspected until the post-mortem material was examined microscopically, and no unfixed tissue or serum was then available for examination. The morphology and staining reactions of the organisms seen in the tissues are those of Cryptococcus, of which genus the common pathogenic species is C. neoformans.

Cryptococcal lesions affect the lungs, meninges and skin in that order of frequency. The most common lung lesion is the subpleural nodule. Involvement of other organs and structures is uncommon, except in the disseminated disease (Littman and Zimmerman, 1956). The cervical and mediastinal lymphadenopathy together with a small granulomatous subpleural lesion seen in the present case could have been ascribed to tuberculosis, except that the appearances of the caseous lymph-nodes were slightly atypical. 
Lymphadenitis due to $C$. neoformans is rare (Littman and Zimmerman; Kent and Layton, 1962). It has been reported only when the disease has become disseminated with involvement of many organs (Symmers, 1953; Kent and Layton). Cervical and mediastinal lymphadenitis does not appear to have been described in association with subpleural lesions of cryptococcosis (Littman and Zimmerman; Kent and Layton). Haugen and Baker (1954) described six cases in which subpleural cryptococcal lesions, similar to the one observed in the present case, were found incidentally at necropsy. In spite of careful examination they were unable to show lymphatic spread to the peribronchial lymphnodes. Two of their cases had extrapulmonary infection involving the meninges, and in one of these there was involvement of the spleen, liver, prostate and kidney.

The tissue reaction observed in the present case is very unusual. Necrosis is not very common in cryptococcosis, in which the most common tissue reaction is a non-necrotising, tuberculoid granulomatous lesion, the cellular content of which may vary. Thus at one end of the scale the lesion may be cellular and fibrous, and at the other it may consist of a large number of cryptococci with no inflammatory cellular reaction or fibrosis. According to Cox and Tolhurst (1946) caseation necrosis is rare. Small foci of caseation necrosis were occasionally observed in the subpleural lesions reported by Haugen and Baker, but to find it on a large scale is most unusual. Indeed its occurrence has been denied by some authorities, although this view is not justified (Symmers, 1968, personal communication).

Cryptococcal infection has been associated with lymphoreticular neoplasms and leukaemia (Zimmerman and Rappaport, 1954; Symmers, 1966), with steroid treatment (Goldstein and Rambo, 1962), with debilitating diseases like sarcoidosis (Littman and Zimmerman; Plummer, Symmers and Winner, 1957) and with cirrhosis of the liver (Goldstein and Rambo; Kent and Layton). The association of cryptococcosis with diabetes has not been established, but the disease has been seen in patients with severe, unstable diabetes (Symmers, 1968, personal communication).

Our patient did not suffer from any lymphoreticular malignancy, and had not been treated with steroids or other immunosuppressive drugs. The mild diabetes was discovered only $5 \mathrm{mth}$ before the terminal illness and had been easily controlled by diet until then. In a considerable number of cases no predisposing condition is found. Two cases of this type were reported recently (Watkins et al.), and we consider that the present case belongs to this category.

The formation of " pseudo-hyphae" by C. neoformans is distinctly uncommon, and indeed some authors consider that it does not occur in tissue or exudates (Moss and McQuown, 1953), but it has been seen in other human cases of cryptococcal infection with caseous lesions (Symmers, 1968, personal communication). Cox and Tolhurst observed hyphal projections from organisms in ventricular fluid obtained after death from one case of encephalitic cryptococcosis. The same strain when injected into animals frequently produced hyphal projections. The organism isolated from one of the cases reported by Symmers (1953) produced “ pseudo-hyphae " when injected intraperitoneally 


\section{CRYPTOCOCCAL LYMPHADENITIS}

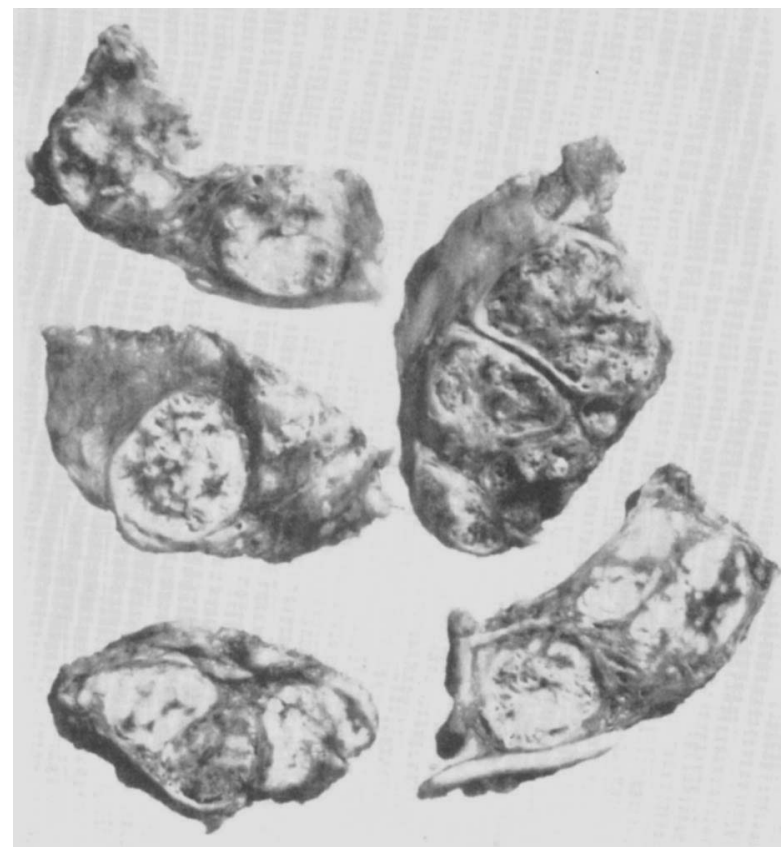

FIG. 1.- The enlarged cervical and mediastinal lymph-node groups. Natural size.

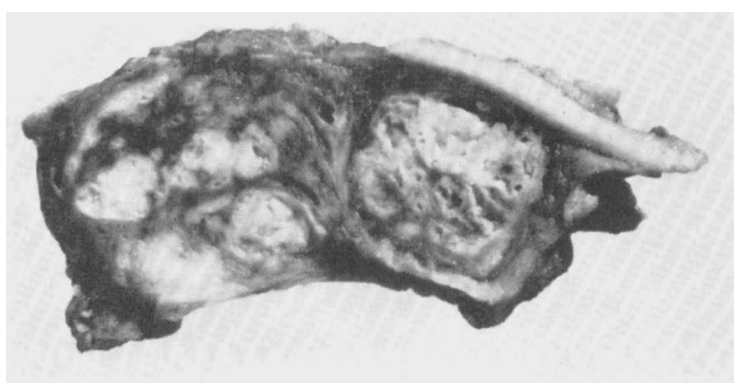

FIG. 2.-Matted lymph-nodes showing nodular pattern with extensive caseation necrosis. $\times 1 \cdot 5$. 
CRYPTOCOCCAL LYMPHADENITIS

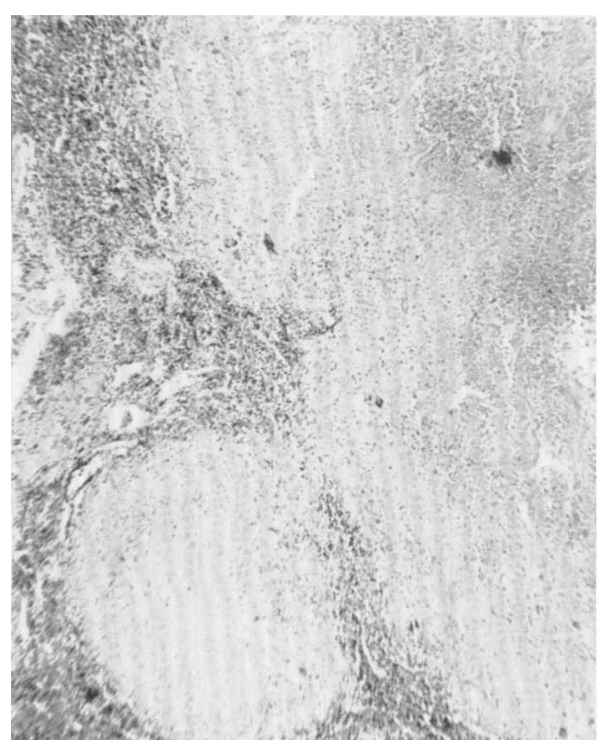

FIG. 3.-Low-power view of lymph-node: extensive caseation and a narrow rim of granulation tissue. Haematoxylin and eosin (HE). $>14$.

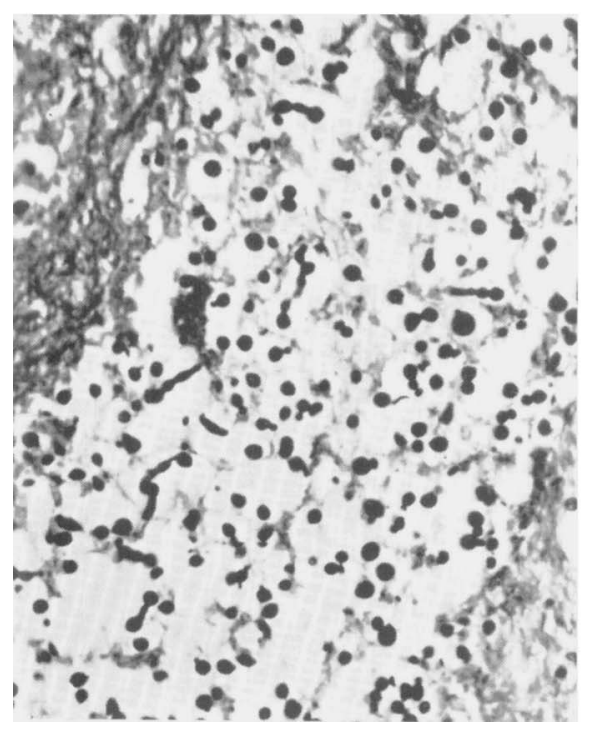

FiG. 5.-Numerous cryptococci within an affected node. Methenamine silver. $\times 120$.

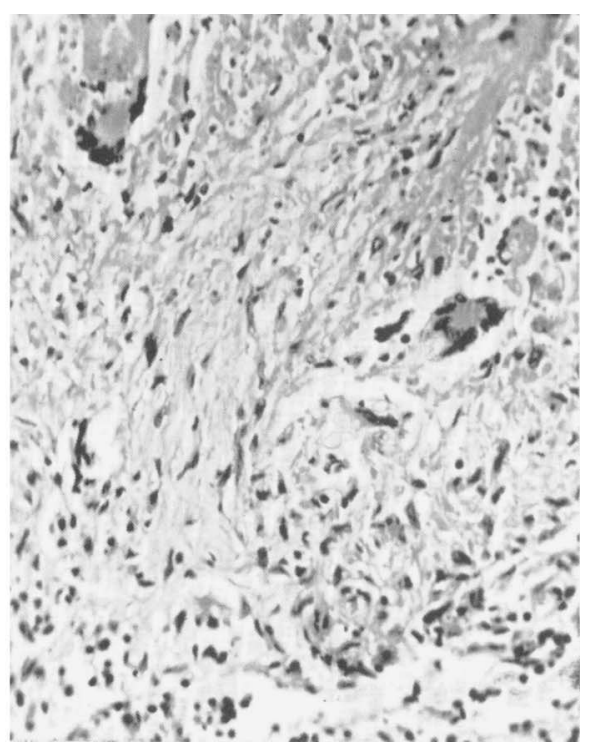

FIG. 4.-Zone of granulation tissue showing Langhans giant cells. HE. $\times 60$.

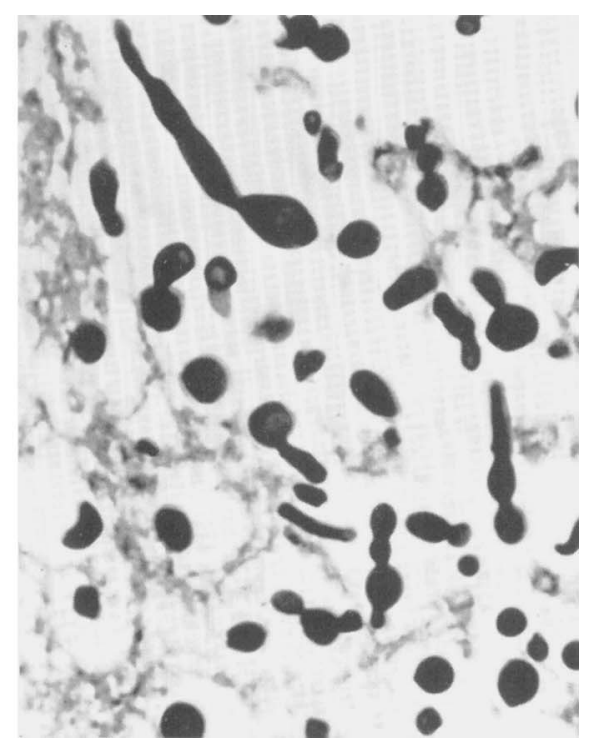

FIG. 6. - Cryptococci, some producing "pseudo-hyphae". Methenamine silver. $\times 320$. 
into mice. Sanfelice (1896) described hyphae in the tissues of animals into which a strain isolated from fruit juice (now considered to be $C$. neoformans) had been injected (Cox and Tolhurst). The production of rudimentary germinal tubes in culture is recognised by several authors (Moss and McQuown; Conant et al., 1954; Emmons, Binford and Utz, 1963).

A strain of $C$. neoformans producing true hyphae from a minority of colonies has been studied by Shadomy and Utz (1966). This organism was in the yeast form when first isolated from an abscess cavity in a patient with coexistent sarcoidosis (Heller et al., 1957).

The paucity of capsular material associated with a considerable tissue reaction in the present case is in accord with the observation of Drouhet (1968) that when the yeast is encapsulated there is generally no tissue reaction, but that decapsulated yeasts are associated with a cellular reaction. We do not know whether the tissue response precludes the formation of capsules or the unencapsulated organism is a more effective stimulus to the inflammatory reaction.

\section{SUMMARY}

A case of cryptococcosis is presented in which there was cervical and mediastinal lymphadenopathy with extensive caseation necrosis. A further unusual finding was the production of " pseudo-hyphae" by the cryptococci in the caseous nodes. There was a single subpleural pulmonary lesion, but only microscopical evidence of meningitis.

We should like to thank Professor W. St.C. Symmers and Professor K. R. Hill for helpful advice, Dr A. G. Beckett, under whom the patient was admitted, for permission to publish the case, and $\mathrm{Mr} \mathrm{C}$. Gilson for the photographs.

\section{REFERENCES}

Conant, N. F., Smith, D. T., BaKer, 1954. In Manual of clinical mycology, 2nd

R. D., Callaway, J. L., and Martin, D. S.

Cox, L. B., and Tolhurst, Jean C. . 1946. Human torulosis, Melbourne.

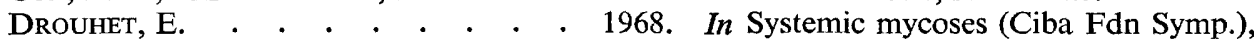
ed. by G. E. W. Wolstenholme and Ruth Porter, London, p. 49.

Emmons, C. W., Binford, C. H., ANd Utz, 1963. Medical mycology, London.

J. P.

Goldstein, E., and Rambo, C. N. 1962. Ann. Intern. Med., 56, 114.

Haugen, R. K., and Baker, R. D. . . 1954. Amer. J. Clin. Path., 24, 1381.

Heller, S., Mclean, Ruth A., CAmpbell, 1957. Amer. J. Med., 22, 986.

Charlotte G., AND Jones, $\mathbf{I}$. $\mathrm{H}$.

KENT, T. H., AND LAYTON, J. M.. . .

LITTMAN, M. L., AND ZiMMERMAN, L. E.

Moss, Emma S., AND McQuown, A. L. .

Plummer, N. S., Symmers, W. St.C., AND WINNER, H. I.

SAnfelice, F. - • - • • • • - 1896. Z. Hyg. InfektKrankh, 21, 32.

ShADOMY, H. J., AND Utz, J. P. . 1966. Mycologia, 58, 383.

1962. Amer. J. Clin. Path., 38, 596.

1956. Cryptococcosis, New York. p. 39.

1957. Br. Med.J., 2, 599.

1953. Atlas of medical mycology, Baltimore, 
Symmers, W. St.C. . . . . . . 1953. Lancet, 2, 1068.

" . . . . . . 1966. In Systemic pathology, ed. by G. Payling Wright and W. St.C. Symmers, London, p. 250.

Watkins, J. S., Campbell, M. J., 1969. Br. Med.J., 3, 29.

GARDNER-MEDWIN, D., INGHAM, H. R.,

AND MURRAY, I. G.

Zimmerman, L. E., and Rappaport, H. 1954. Amer. J. Clin. Path., 24, 1050. 